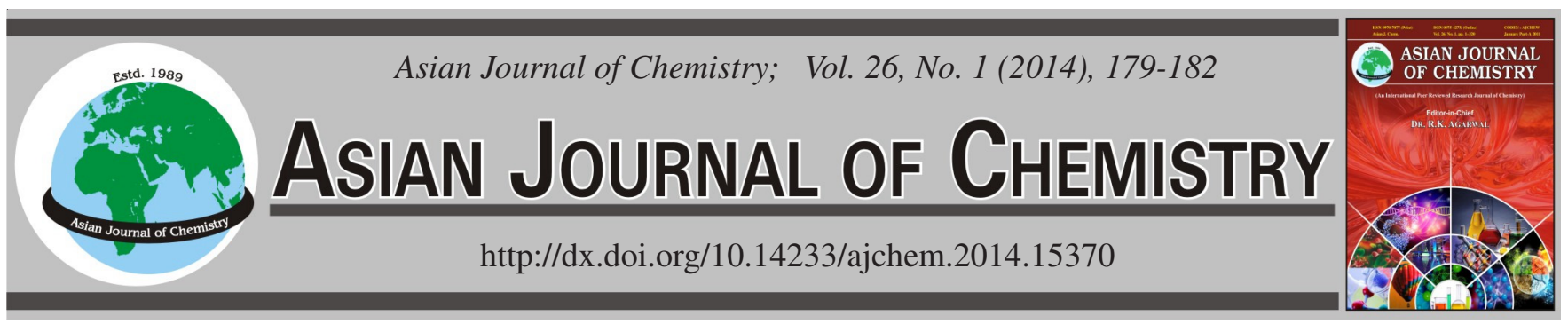

\title{
Morphological Study of Layered Micro Deposits on Platinum Electrode During Potentiometric Titration of Hexadecyltrithiocarbonate with Transition Metal Ions
}

\author{
T. RAJU ${ }^{1, *}$, K. Giribabu ${ }^{2}$ and V. NARAYANAN ${ }^{2, *}$
}

${ }^{1}$ Department of Analytical Chemistry, School of Chemical Sciences, University of Madras, Guindy Maraimalai Campus, Chennai-600 025, India ${ }^{2}$ Department of Inorganic Chemistry, School of Chemical Sciences, University of Madras, Guindy Maraimalai Campus, Chennai-600 025, India

*Corresponding authors: E-mail: proftraju2004@yahoo.com; vnnara@yahoo.co.in

\begin{abstract}
In this work, we report the formation of multilayered micro deposits of $\mathrm{M}(\mathrm{DTTC})_{\mathrm{n}}$ on the platinum electrode during the potentiometric titration of hexadecyltrithiocarbonate (HDTTC) with cobalt(II), nickel(II) and copper(II) ions. The titration was carried out using universal buffer as the buffering agent in order to study the influence of the $\mathrm{pH}$ on the titrimetric analysis. In case of universal buffer, at higher $\mathrm{pH}$ (8-11) the recoveries of hexadecyltrithiocarbonate were found to be $80 \%$, which is an indicative of the formation of polynuclear complex. The formed deposits were studied by using scanning electron microscope and elemental diffraction analysis by X-rays (EDAX). An attempt was made to explain the formation of multilayers on to the platinum electrode.
\end{abstract}

Keywords: Multilayers, SEM, Potentiometric titrations, Platinum electrode, Trithiocarbonate.

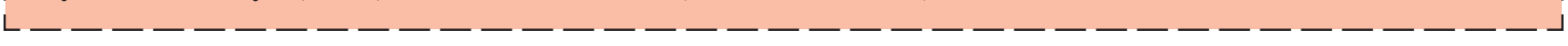

\section{INTRODUCTION}

Trithiocarbonates (TTC) belong to the family of sulphur compounds, the other congener were xanthates, dithocarbamates, dithiophosphates, dixanthogen, etc., Trithiocarbonates were used as floatation agents and as a precursor in the synthesis of metal sulphides ${ }^{1-7}$. The studies on trithiocarbonates were scarce in literature. Trithiocarbonates complexes closely resemble, in all aspects in the possession of hetero atom ' $S$ ' in place of ' $\mathrm{O}$ ' in the case of xanthate. Transition metal complexes of many mono anionic 1,1-dithiolates have been prepared and studied, of these probably the most poorly characterized are the complexes of alkyl trithiocarbonates. In 1961, Schaeffer reported the preparation of some thioxanthate complexes. However, the chemical properties of these compounds were not discussed in detail. Later, Ewald and Sinn reported the isolation of several thioxanthate complexes of $\mathrm{Ni}(\mathrm{II}), \mathrm{Cu}(\mathrm{II}), \mathrm{Co}(\mathrm{III})$ and $\mathrm{Fe}(\mathrm{III})^{8}$. The spectrophotometric method for the determination of $\mathrm{Co}$ and Ni using a new reagent sodium ethyl trithiocarbonate has been described. The yellow coloured cobalt complex and red coloured nickel complex have been extracted quantitatively using carbon tetrachloride in the $\mathrm{pH}$ range of 4-11 and 4.06.7 , respectively. The colours of these complexes are stable and absorptions have been measured at $389 \mathrm{~nm}$ for cobalt and $495 \mathrm{~nm}$ for nickel. complexes ${ }^{9-15}$. From the literature, it is clear that the potentiometric study using trithiocarbonates were scarce. So we have developed a potentiometric method to estimate the trithiocarbonates and also insights were made in the electrode deposits, which may open up a new era in the potentiometric sensors.

\section{EXPERIMENTAL}

Potentiometric titrations were performed with Elico (India) $\mathrm{pH}$ meter of model LI 120, using bright platinum electrode and saturated calomel electrode as the working and reference electrodes, respectively.

SEM-EDAX studies: All the adsorbed complex species on platinum electrodes were subjected to SEM-EDAX analysis for the surface study and chemical constituents. Aim and shoot methodology were performed by using Hitachi S-3400 scanning electron microscope equipped with X-ray microanalysis. Before recording the images of the adsorbed complexes on the platinum electrode surface, a reference imaging and EDAX analysis were performed for the plain platinum electrode. The platinum electrode was cleaned by sonication with $5 \mathrm{M}$ hydrochloric acid to remove the impurities from the electrode and rinsed with double distilled water twice to remove the acid from the electrode surface.

All the chemicals used were of Analar grade reagents and used as received. Double distilled water was used throughout the work. Diethyl ether, hexadecylthiol, dimethylformamide and chloroform were bought from E-Merck. Potassium hydroxide, sodium acetate and sodium carbonate were from Sisco Research Laboratories (India). Cobaltous chloride, nickel 
acetate and copper sulphate were from Central Drug House (India).

\section{Solutions}

Potassium salt of hexadecyl trithiocarbonate: The potassium salt of hexadecyltrithiocarbonate was prepared by the drop wise addition of $6 \mathrm{~mL}$ carbon disulphide to $10 \mathrm{~mL}$ hexadecylthiol in the presence of $2 \mathrm{~mL} 0.01 \mathrm{M}$ potassium hydroxide; the contents were cooled and maintained at less than $5^{\circ} \mathrm{C}$ with constant vigorous stirring for $0.5 \mathrm{~h}$. The yellow solid obtained was filtered and washed with diethyl ether and then dried at room temperature overnight.

The $0.05 \mathrm{M}$ cobalt chloride, nickel sulphate and copper sulphate solutions were prepared in $250 \mathrm{~mL}$ of distilled water in volumetric flasks.

\section{RESULTS AND DISCUSSION}

The potentiometric titration was carried out by taking metal salt into the burette and hexadecyltrithiocarbonate solution in a $50 \mathrm{~mL}$ beaker. The $1 \mathrm{~cm}^{2}$ platinum plate was used as the working electrode and calomel electrode as the reference electrode. The $\mathrm{pH}$ of the solution was adjusted to required $\mathrm{pH}$ by using potentiometer equipped with glass electrode as the working electrode. Each addition of the metal salt from the burette was fixed to be $1 \mathrm{~mL}$ and the titration was carried out under stirring condition.

The different types of reaction that takes place in the solution and with electrode material:

Stage-1: At the electrode: At the electrode (being more positive and anodic in nature) the HDTTC ion being more negative is attracted very strongly due to coulombic interaction, hence adsorption overcoming the outer and inner Helmholtz plane which lead to the formation of complex at the electrode material $^{9-12}$ takes place, which is pictorially represented in Fig. 1.
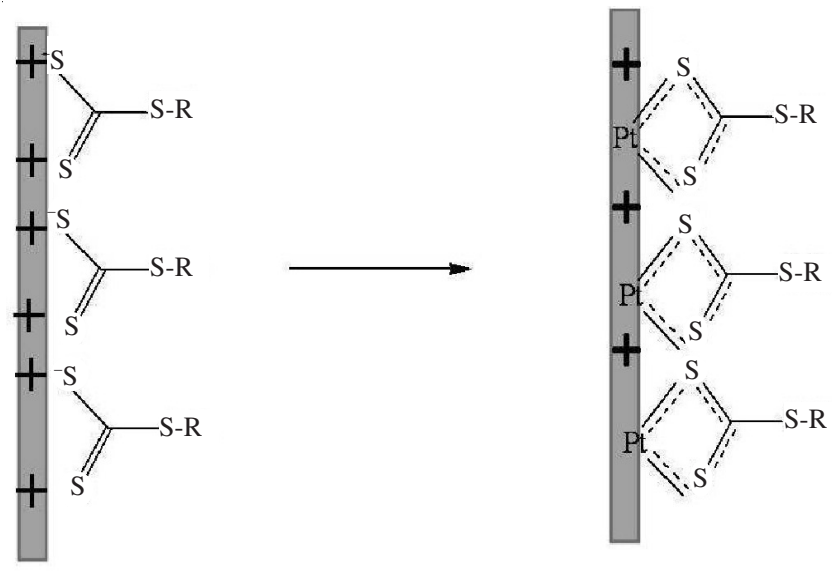

$\mathrm{R}=\mathrm{C}_{16} \mathrm{H}_{33}$

Fig. 1. Schematic representation of adsorption of HDTTC on to the platinum electrode

Since a lone pair of electrons was available on the other sulphur atom and being in close proximity with the metal electrode, the unique cyclization (four membered ring formation on complexation) which is characteristic of dithio ligands takes place followed by complexation.
Stage-2: Bulk of the solution: At the beginning of the titration with metal ions, the metal ion forms complex with HDTTC available in the bulk of the solution in 1:2 (M:L) ratio.

$$
2 \mathrm{C}_{16} \mathrm{H}_{33} \mathrm{SCSS}^{-} \mathrm{K}^{+}+\mathrm{M}^{2+} \longrightarrow\left(\mathrm{C}_{16} \mathrm{H}_{33} \mathrm{SCSS}\right)_{2} \mathrm{M}+2 \mathrm{~K}^{+}
$$

Stage-3: Interaction of metal ions with electrode and its surface complexes: As the titration progressed, the available excess metal ions compete with the electrode to form complex with the adsorbed HDTTC on the electrode surface owing to the higher stability of the metal complex formed. The complex formed on the electrode surface may be a mixed hetero bimetallic complex of platinum and metal ions. This takes place at the surface of electrode and thereby making the electrode surface unavailable for sensing the ongoing reaction i.e., sensing ability decreases with time. Ultimately, an uniform layer of electrode surface deposit, which composed of the ligand, metal ions and platinum occurs. On further titration multilayer deposits may also be formed. The multilayer deposits on the electrode surface were further examined by SEM and EDAX.

Potentiometric titration of hexadecyltrithiocarbonate (HDTTC) with cobaltous chloride towards platinum electrode in presence of universal buffer: Fig. 2 shows the titration of HDTTC with cobalt ions in presence of universal buffer and without buffer. The graph without the presence of universal buffer indicates the randomness and multitude of reaction takes place. The starting potential was very compact $(-340$ to $-240 \mathrm{mV})$ at all $\mathrm{pH}$ values. As the titration proceeds the potential for higher $\mathrm{pH}$ values falls to the less negative side from $(-260$ to $-50 \mathrm{mV})$. All mechanistic paths of adsorption followed by complexation at the electrode and the complexation that takes place in the bulk of the solution. The deposit on the platinum electrode was further examined by SEM and EDAX in order to study the morphology of the deposit and the elements present in it. Fig. 2a shows the SEM images of the cobalt HDTTC deposit on the platinum electrode. The morphology was found to be highly agglomerated spherical particles. The electrode surface was examined at different magnifications of 50, $4010 \mu \mathrm{m}$. The morphology of the deposit was uniform in all over the surface of the platinum electrode.

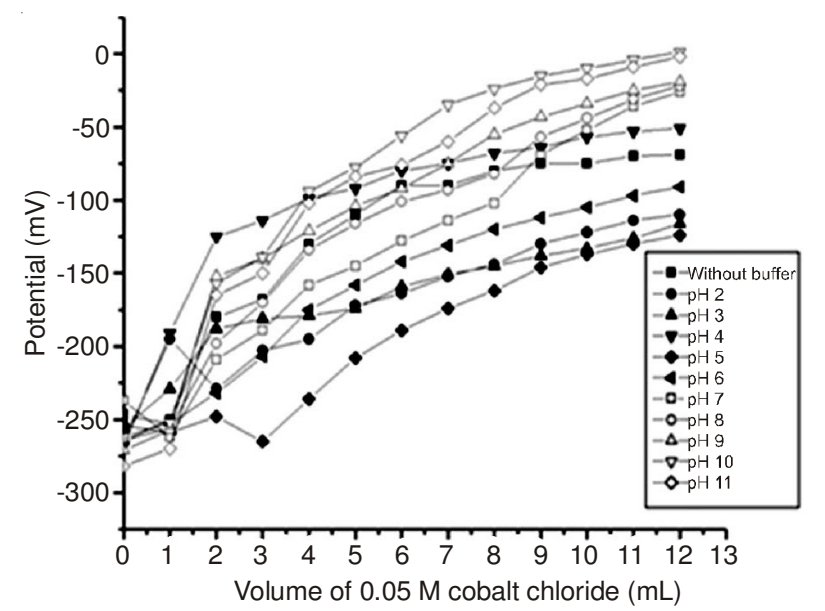

Fig. 2. Titration curves of $0.05 \mathrm{M}$ HDTTC with $0.05 \mathrm{M}$ cobalt chloride in presence of universal buffer $(\mathrm{pH}, 2-11)$ using platinum electrode 

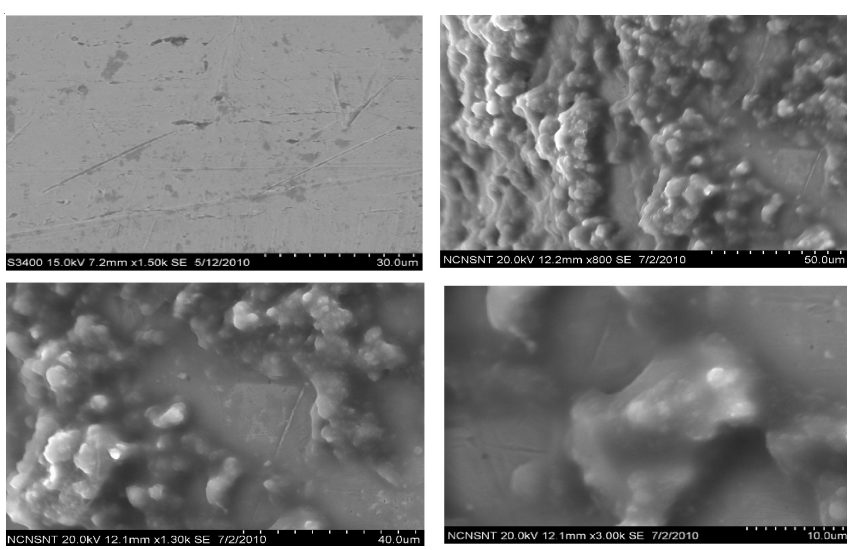

Fig. 2. (a) SEM image of cobalt HDTTC deposit onto the platinum electrode surface

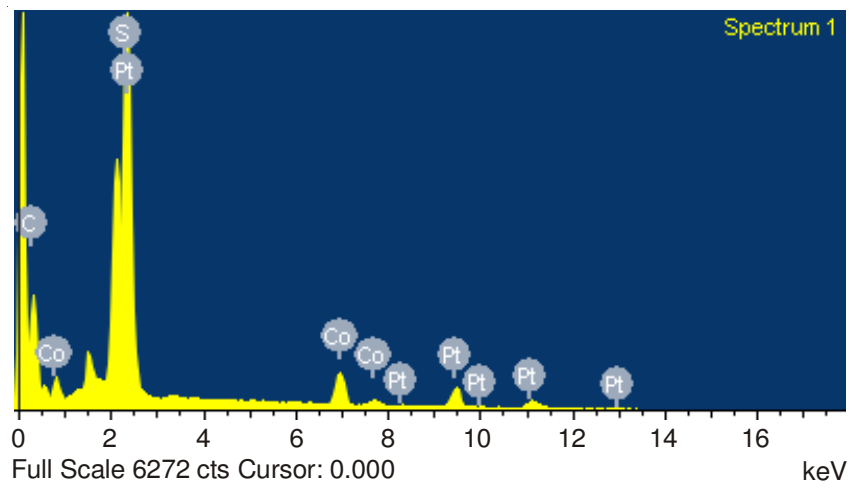

Fig. 2. (b) EDAX spectrum of cobalt HDTTC deposit onto the platinum electrode surface

Potentiometric titration of hexadecyltrithiocarbonate (HDTTC) with nickel(II) chloride towards platinum electrode in presence of universal buffer: Fig. 3 shows the titration of HDTTC with nickel ions in presence of universal buffer and without buffer. The quantification results were only $50 \%$. The shape of the graph was ' $\mathrm{S}$ ' shape. The starting and final potential was very compact for the curves above $\mathrm{pH} 7$, but a change in compactness of the potential during the titration is observed in the $\mathrm{pH}$ range 2-7. The starting potentials were in the range of -275 to $-240 \mathrm{mV}$ for all the $\mathrm{pH}$ values. Electrode surface adsorption followed by multilayer deposition was also observed. The investigation of the electrode deposit using SEM and EDAX by AIM and SHOOT methodology was shown in Fig. 4a-b. The same trend was followed when the titration was carried out using copper sulphate but the quantification was found to be $80 \%$ which is shown in Fig. 5. The SEM and EDAX analysis was shown in Fig. 5a-b. The morphology formed for nickel ions were agglomerated microclusters with few isolated pear shaped nanoparticles.

The quantification of HDTTC was not achieved completely because of the deposition of the HDTTC over the platinum electrode which in turn affects the sensing of the electrode of the ongoing complexation reaction. The morphology formed for copper ions were agglomerated microclusters, consisting of micro rods. The morphology of the deposits on the platinum electrode was different for different metal ions. From this it is clear that the interaction of individual metal ion with HDTTC was different which forms different deposits. The environment

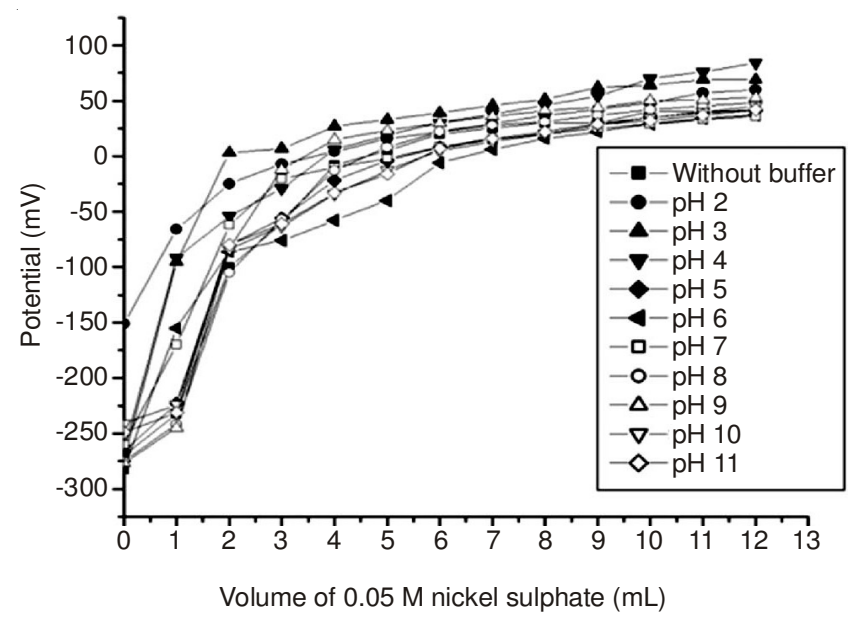

Fig. 3. Titration curves of $0.05 \mathrm{M}$ HDTTC with $0.05 \mathrm{M}$ nickel sulphate in presence of universal buffer $\mathrm{pH}$ (2-11) using platinum electrode
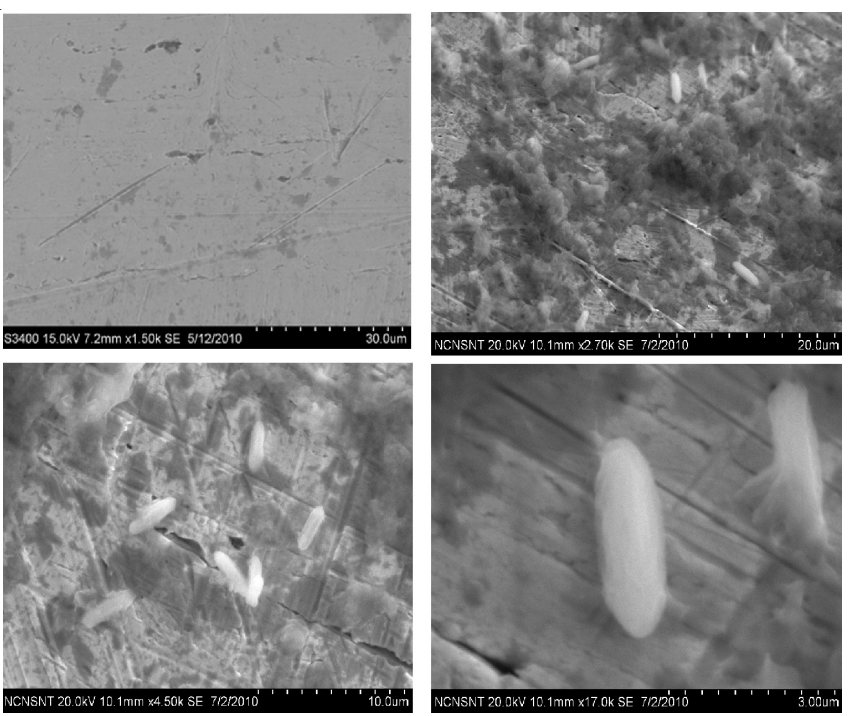

Fig. 4. (a) SEM image of nickel HDTTC deposit onto the platinum electrode surface

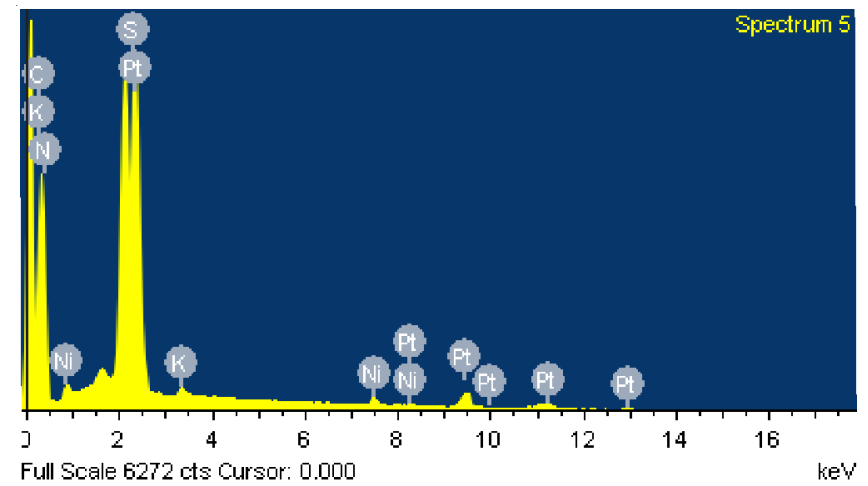

Fig. 4. (b) EDAX spectrum of nickel HDTTC deposit onto the platinum electrode surface

of interaction between the cobalt ion and HDTTC may be tetrahedral while square planar for nickel and copper ions ${ }^{15-20}$.

\section{Conclusion}

The formation of deposit on the electrode was investigated by using SEM and the elemental composition of the complex was further evidenced by EDAX. The titration of 


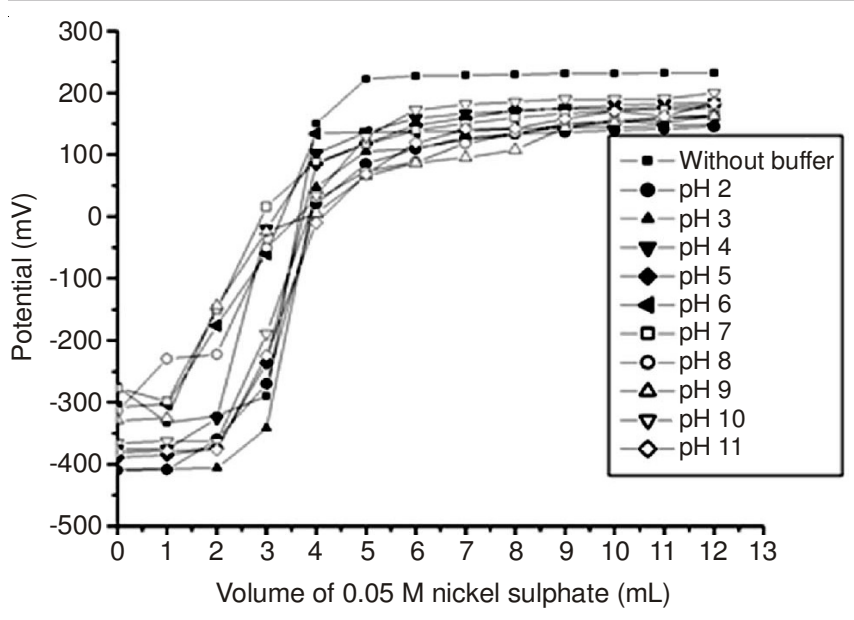

Fig. 5. Titration curves of $0.05 \mathrm{M}$ HDTTC with $0.05 \mathrm{M}$ copper sulphate in presence of universal buffer $\mathrm{pH}$ (2-11) using platinum electrode
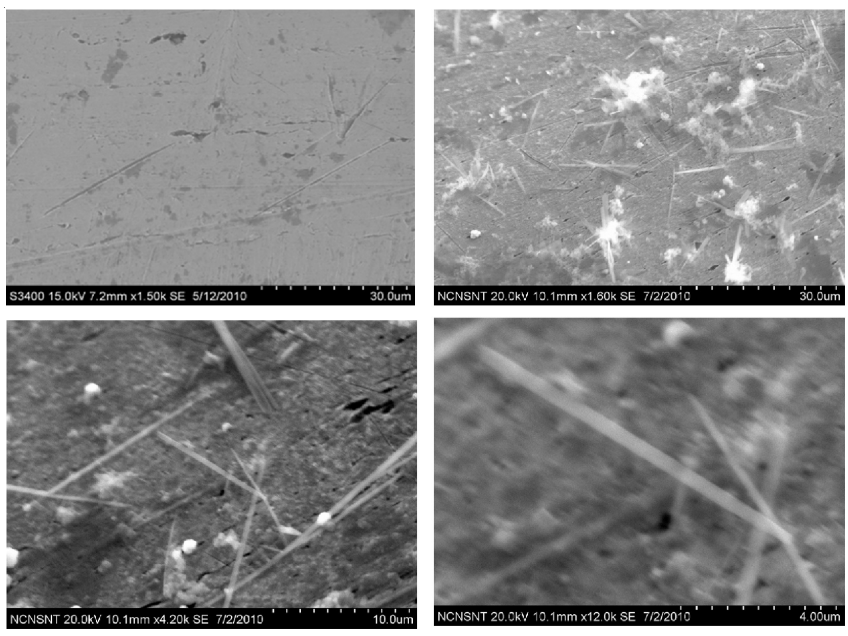

Fig. 5. (a) SEM image of copper HDTTC deposit onto the platinum electrode surface

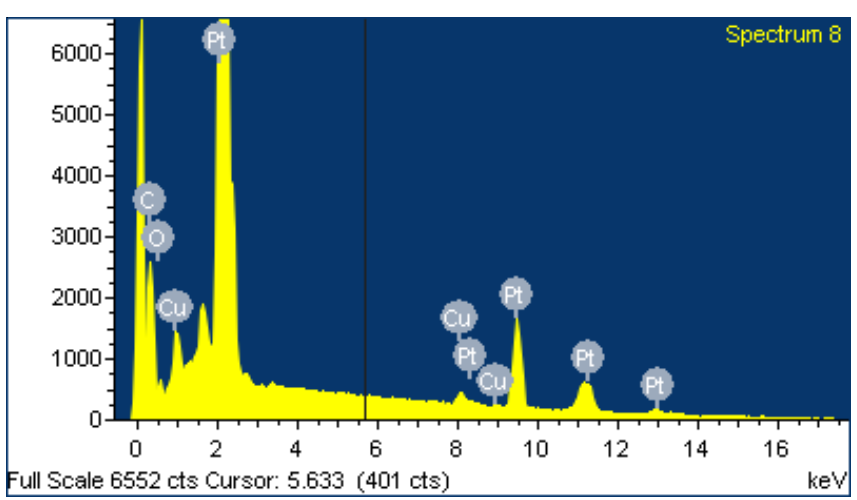

Fig. 5. (b) EDAX spectrum of copper HDTTC deposit onto the platinum electrode surface cobalt, nickel and copper ions with HDTTC was carried out in different $\mathrm{pH}$ but the quantification was not satisfactory due to the formation of the deposit on to the platinum electrode. The formation of microclusters, pear shaped particle and micro rods were formed for cobalt, nickel and copper ions when used for the titration.

\section{ACKNOWLEDGEMENTS}

One of the authors (KG) wish to thank Department of Science and Technology (DST), Government of India for the financial assistance in the form of INSPIRE fellowship (Inspire Fellow no: 10226) under the AORC scheme. National Centre for Nanoscience and Nanotechnology (NCNSNT), University of Madras for recording FE-SEM and EDAX.

\section{REFERENCES}

1. S. Chaudhari and V. Tare, Water Sci. Technol., 34, 161 (1996).

2. S. Chaudhari and V. Tare, J. Appl. Polym. Sci., 71, 1325 (1999).

3. A. Kumar, N.N. Rao and S.N. Kaul, Bioresour. Technol., 71, 133 (2000).

4. D. Marani, M. Mezzana, R. Passino and G. Tiravanti, Environ. Technol. Lett., 1, 141 (1980).

5. V. Tare and S. Chaudhari, Water Res., 21, 1109 (1987).

6. R.E. Wing, Environ. Prog., 2, 269 (1987).

7. D. Marani, M. Mezzana, R. Passino and G. Tiravanti, Environ. Technol. Lett., 1, 141 (1980)

8. A.H. Ewald, R.L. Martin, E. Sinn and A.H. White, Inorg. Chem., 8, 1837 (1969).

9. C.A. Fustin and A.S. Duwez, J. Electron Spectrosc. Relat. Phenom., 172, 104 (2009).

10. A.S. Duwez, P. Guillet, C. Colard, J.F. Gohy and C.A. Fustin, Macromolecules, 39, 2729 (2006).

11. J.A. Venter and M.K.G. Vermaak, Minerals Eng., 21, 559 (2008).

12. G. Ingram and B.A. Toms, J. Chem. Soc., 4328-4344 (1957).

13. K.V. Muralikrishna, B. Polaiah and B. Rangamannar, Asian J. Chem., 6, 917 (1994).

14. B.S. Rao, S.S. Dube, A.V.D. Nagendrakumar and B.S. Reddy, Asian J. Chem., 22, 7567 (2010).

15. B.K. Dwivedi, H.N. Mehrotra and D. Mehrotra, Asian J. Chem., 3, 58 (1991).

16. P.D. Beer, A.R. Cowley, J.C. Jeffery, R.L. Paul and W.W.H. Wong, Polyhedron, 22, 795 (2003)

17. N. Revaprasadu and S.N. Mlondo, Pure Appl. Chem., 78, 1691 (2006).

18. C. Chieh and K.J. Moynihan, Acta Cryst., B36, 1367 (1980).

19. Z. Trávnícek, M. Malon and Z. Sindelár, Transition Met. Chem., 24, 38 (1999).

20. K. Yamuna, V.V. Ramana, K.A. Emmanuel and K. Saraswati, Asian J. Chem., 4, 387 (1992) 